\title{
Case report: tracheoesophageal fistula secondary to post- intubation tracheomegaly in a tetanus patient
}

\author{
Weisheng Chen ${ }^{1 \#}$, Jiaxin Li $^{2 \#}$, Ronghua Deng ${ }^{1}$, Chunbo Chen ${ }^{3}$ \\ ${ }^{1}$ Department of Emergency Intensive Care Unit, Huizhou Third People's Hospital, Guangzhou Medical University, Huizhou, China; ${ }^{2}$ Department \\ of Intensive Care Unit of Cardiac Surgery, Guangdong Cardiovascular Institute, Guangdong Provincial People's Hospital, Guangdong Academy of \\ Medical Sciences, Guangzhou, China; ${ }^{3}$ Department of Critical Care Medicine, Maoming People's Hospital, Maoming, China \\ \#These authors contributed equally to this work. \\ Correspondence to: Chunbo Chen. Department of Critical Care Medicine, Maoming People's Hospital, 101 Weimin Rd, Maoming, China. \\ Email: gghccm@163.com.
}

\begin{abstract}
Tracheomegaly and tracheoesophageal fistula (TEF) may be complicated within 12-200 days (with a mean of 43 days) of mechanical ventilation but rare in short-term intubation. Here we present a case of TEF secondary to post-intubation tracheomegaly in a tetanus patient. A 49-year-old male was admitted to the emergency room (ER) and diagnosed with tetanus. He became intubated and mechanically ventilated, but showed over-inflation of the endotracheal tube cuff on X-ray and chest computed tomography since the 8 th day. After extubation, the patient had severe coughing during eating. Fiberoptic bronchoscopy and gastroscopy demonstrated a TEF located at the anterior wall of the esophagus. Esophageal exclusion and jejunostomy were performed to heal the fistula. The recurrent and uncontrollable muscular rigidity and spasms might be the main cause early tracheomegaly and TEF. Short-term intubation induced TEF should be aware of in specific patients. Both cuff pressure and cuff volume should be monitored to minimize tracheoesophageal injuries in such cases.
\end{abstract}

Koywords: Case report; tracheoesophageal fistula (TEF); tracheomegaly; tetanus; endotracheal tube cuff

Submitted Dec 26, 2019. Accepted for publication Jul 27, 2020.

doi: 10.21037/apm-19-681

View this article at: http://dx.doi.org/10.21037/apm-19-681

\section{Introduction}

Tracheomegaly is characterized by over-dilation of trachea. It is usually associated with congenital disease, MounierKuhn syndrome (1), and prolonged ventilation (2). Tracheoesophageal fistula (TEF) is also a rare complication that mostly occurs after malignancies, infection, ruptured diverticula, and injuries (3). Post-intubation TEF is a severe complication in patients that require prolonged mechanical ventilation. TEF may be complicated within 12-200 days (with a mean of 43 days) of mechanical ventilation but rare in short-term intubation $(4,5)$. Surgical factors and traumatic injury may lead to short-term acquired TEF within 1-15 days (6). However, in non-surgical and nontraumatic cases, TEF is rare in short-term intubation. Here we present a case of TEF secondary to tracheomegaly in a tetanus patient, who developed this rare complication since the 8 th day of intubation. We present the following case in accordance with the CARE reporting checklist (available at http://dx.doi.org/10.21037/apm-19-681).

\section{Case presentation}

A 49-year-old male was admitted to the emergency room (ER) with a 10-day history of left hand trauma, and a 3-day history of trismus and limbs convulsion. He had no special previous medical and family history and relevant past interventions. Physical examination at admission showed his temperature was 36.8 degrees Celsius, his blood pressure was $124 / 92 \mathrm{mmHg}$ and heart rate was 103 beats per min. The patient showed typical symptoms of tetanus infection including locking of the jaw and muscular stiffness of his 

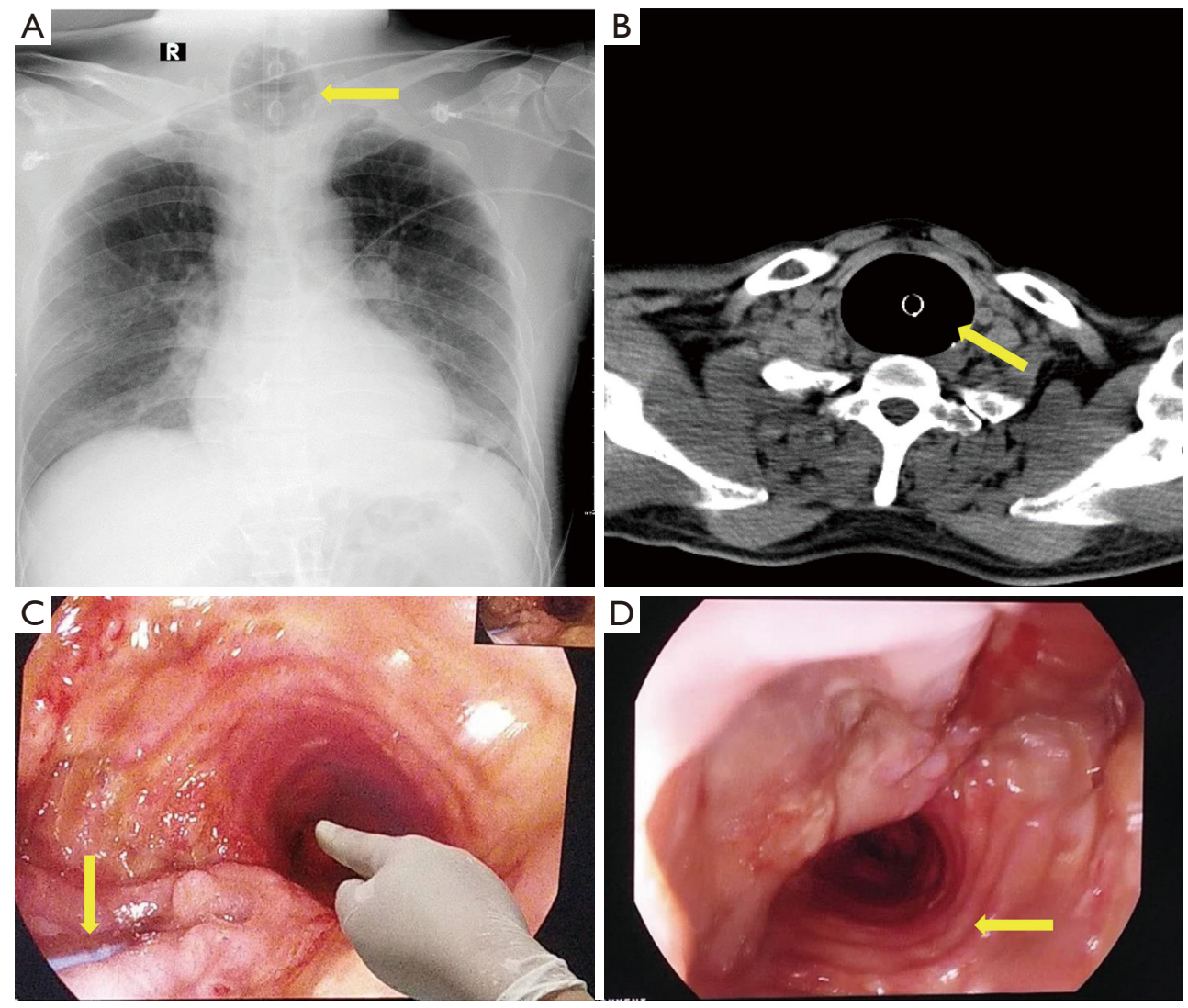

Figure 1 Tracheomegaly and TEF were recognized by image examinations and gastroscope. (A) Chest X-ray showed enlargement of the endotracheal tube cuff (arrow); (B) chest CT showed the inflated endotracheal tube cuff and the gastric tube (arrow); (C) the absence of anterior esophageal wall, posterior tracheal wall and the blue gastric tube (arrow) can be seen when the gastroscope entered the esophagus; (D) gastroscope entered the airway through the fistula located at the anterior esophageal wall, showing the tracheal cartilage rings (arrow). TEF, tracheoesophageal fistula.

neck and limbs. He was diagnosed with tetanus and treated with tracheal intubation, wound debridement, and tetanus antitoxin. From the $8^{\text {th }}$ day, chest $\mathrm{X}$-ray and computed tomography (CT) showed enlargement of the endotracheal tube cuff twice (Figure 1A). Each time the cuff pressures were normal, and the endotracheal tubes were promptly replaced. Until the $19^{\text {th }}$ day, the patient was relieved from tetanus symptoms and weaned from ventilation. Before extubation, chest CT showed over-inflation of the endotracheal tube cuff (Figure 1B). After extubation, the patient had severe coughing during eating. Fiberoptic bronchoscopy and gastroscopy demonstrated a TEF located at the anterior wall of the esophagus (Figure 1C,D). Esophageal exclusion and jejunostomy were performed to heal the fistula. However, three days later the patient left hospital against advice and lost follow-up (Figure 2).
All procedures performed in studies involving human participants were in accordance with the ethical standards of the institutional research committee and with the Helsinki Declaration (as revised in 2013). Written informed consent was obtained from the patient for publication of this manuscript and any accompanying images.

\section{Discussion}

Acquired TEF is an uncommon complication that develops within a wide time range due to different causes: surgical causes 1-5 days, traumatic injury 5-15 days, local infection 15-21 days, and tracheal cuff-related injury 21-30 days (6). In non-surgical and non-traumatic cases, TEF is rare in short-term intubation (7). In our current case, a tetanus patient developed TEF in the 8 th day of intubation, 


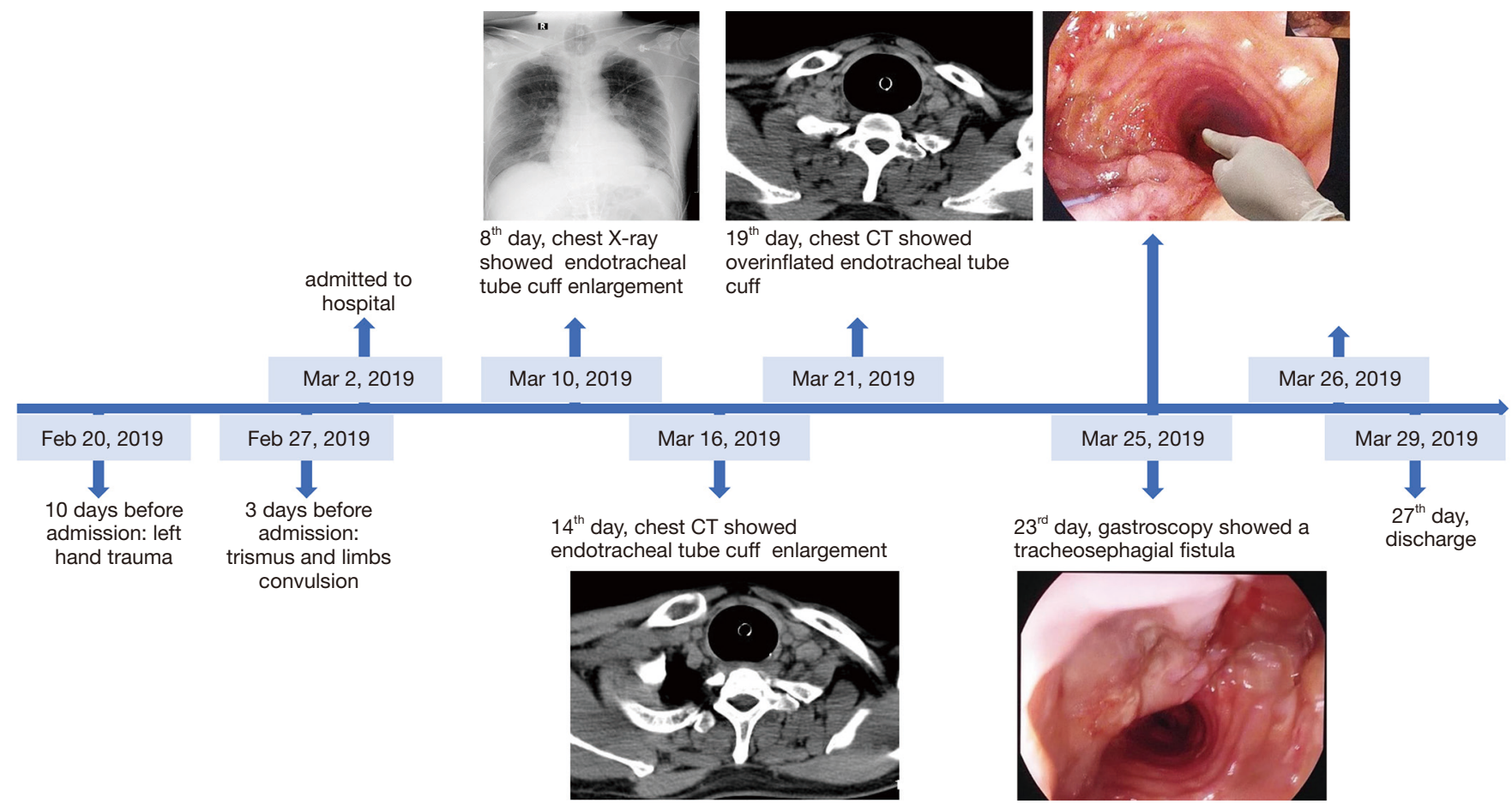

Figure 2 The timeline of the patient exhibits tracheoesophageal fistula secondary to tracheomegaly by chest X-ray, chest CT, and endoscope.

suggesting that tetanus might be a special and noteworthy risk factor of short-term TEF in non-surgical patient.

Tetanus causes muscular stiffness in the jaw followed by stiffness of the neck, difficulty in swallowing, rigid abdominal muscles, generalized spasms, sweating, and fever. Patient with tetanus in this case had recurrent and uncontrollable muscular rigidity and spasms, which exerted additional pressures on the tracheal wall. In some case high cuff pressure might cause uncommon complication such as vertebral erosion (8). However, in our case the cuff pressures were within normal range. Thus we speculate that the extra pressure due to tetanus symptoms might be the main cause of endotracheal tube cuff dysfunction, early tracheomegaly and TEF.

In this case, other risk factors of early tracheomegaly and TEF include prolonged intubation, excessive tube movement, respiratory infections, and the use of a nasogastric tube. These factors might worsen the vulnerability of the tracheal mucosa and cause tracheoesophageal injuries. Apart from cuff pressure, cuff volume should be monitored to prevent the endotracheal cuff from over-inflation. Endotracheal tube cuff pressures and volumes should be monitored and kept within ideal ranges (cuff pressures range $20-30 \mathrm{cmH}_{2} \mathrm{O}$, cuff volumes range $6-8 \mathrm{~mL}$ ) to prevent tracheal injury in critically ill patients.

In patients suffering post-intubation TEF, surgical treatment is the only solution especially for large dimension fistula (9). However, the types of procedure and the timing of intervention are debatable. In our case, esophageal exclusion and jejunostomy were performed after the patient was stable and extubated. For other patients who are unstable or rely on ventilation, comprehensive and individualized management could lead to satisfactory outcomes.

In this case, early tracheomegaly and TEF were recognized promptly by several means of examination, and corresponding proactive treatments were performed such as replacing endotracheal tubes, esophageal exclusion and jejunostomy. However, the limitation of this case is that image examinations attracted more attention than comprehensive auxiliary tests concerning the airway. Lesions might occur before the images unveiled them. Therefore, careful examinations and scrutiny cannot be overemphasized in critically ill patients.

In summary, comprehensive management of endotracheal tube could avoid uncommon and severe complications such as tracheomegaly and TEF in patients with tetanus. 


\section{Acknowledgments}

Funding: The study was supported by High-level Hospital Construction Research Project of Maoming People's Hospital.

\section{Footnote}

Reporting Checklist: The authors have completed the CARE reporting checklist. Available at http://dx.doi.org/10.21037/ apm-19-681

Conflicts of Interest: All authors have completed the ICMJE uniform disclosure form (available at http://dx.doi. org/10.21037/apm-19-681). The authors have no conflicts of interest to declare.

Ethical Statement: The authors are accountable for all aspects of the work in ensuring that questions related to the accuracy or integrity of any part of the work are appropriately investigated and resolved. All procedures performed in studies involving human participants were in accordance with the ethical standards of the institutional research committee and with the Helsinki Declaration (as revised in 2013). Written informed consent was obtained from the patient for publication of this manuscript and any accompanying images.

Open Access Statement: This is an Open Access article distributed in accordance with the Creative Commons Attribution-NonCommercial-NoDerivs 4.0 International License (CC BY-NC-ND 4.0), which permits the noncommercial replication and distribution of the article with the strict proviso that no changes or edits are made and the original work is properly cited (including links to both the formal publication through the relevant DOI and the license). See: https://creativecommons.org/licenses/by-nc-nd/4.0/.

\section{References}

1. Krustins E, Kravale Z, Buls A. Mounier-Kuhn syndrome or congenital tracheobronchomegaly: a literature review. Respir Med 2013;107:1822-8.

2. Giudice M, Gallo S, Maffioli MP, et al. Acquired tracheal dilatation after prolonged ventilation: an unusual treatment option. Laryngoscope 2014;124:2309-12.

3. Reed MF, Mathisen DJ. Tracheoesophageal fistula. Chest Surg Clin N Am 2003;13:271-89.

4. Marzelle J, Dartevelle P, Khalife J, et al. Surgical management of acquired post-intubation tracheooesophageal fistulas: 27 patients. Eur J Cardiothorac Surg 1989;3:499-502; discussion 502-3.

5. Kucuk C, Arda K, Ata N, et al. Tracheomegaly and tracheosephagial fistula following mechanical ventilation: A case report and review of the literature. Respir Med Case Rep 2016;17:86-9.

6. Kaur D, Anand S, Sharma P, et al. Early presentation of postintubation tracheoesophageal fistula: Perioperative anesthetic management. J Anaesthesiol Clin Pharmacol 2012;28:114-6.

7. Rana R, Sapkota R, Shakya B, et al. Prolonged Intubation Induced Tracheoesophageal Fistula in Suspected Meningococcal Sepsis with ARDS: A Case Report. JNMA J Nepal Med Assoc 2018;56:980-982.

8. Petrache I, Patel D, Wolf KM, et al. Vertebral erosion: an uncommon complication of tracheal tubes. Am J Respir Crit Care Med 2014;190:e4.

9. Bolca C, Păvăloiu V, Fotache G, et al. Postintubation Tracheoesophageal Fistula - Diagnosis, Treatment and Prognosis. Chirurgia (Bucur) 2017;112:696-704.
Cite this article as: Chen W, Li J, Deng R, Chen C. Case report: tracheoesophageal fistula secondary to postintubation tracheomegaly in a tetanus patient. Ann Palliat Med 2021;10(4):4922-4925. doi: 10.21037/apm-19-681 